This item was submitted to Loughborough's Research Repository by the author.

Items in Figshare are protected by copyright, with all rights reserved, unless otherwise indicated.

\title{
How do international advertisers use consumer culture positioning strategies? A cross-national, cross-category approach
}

PLEASE CITE THE PUBLISHED VERSION

https://doi.org/10.1108/IMR-05-2020-0101

\section{PUBLISHER}

Emerald Publishing Limited

VERSION

AM (Accepted Manuscript)

\section{PUBLISHER STATEMENT}

This paper was accepted for publication in the journal International Marketing Review and the definitive published version is available at https://doi.org/10.1108/IMR-05-2020-0101.

LICENCE

CC BY-NC 4.0

\section{REPOSITORY RECORD}

Michaelidou, Nina, Milena Micevski, and Georgios Halkias. 2020. "How Do International Advertisers Use Consumer Culture Positioning Strategies? A Cross-national, Cross-category Approach”. Loughborough University. https://hdl.handle.net/2134/12620741.v1. 


\title{
How do International Advertisers use Consumer Culture Positioning Strategies? A Cross- national, Cross-category Approach
}

\begin{abstract}
Purpose - The present paper explores how advertisers use consumer culture positioning (CCP) strategies in advertising across countries and product categories.

Design/methodology - The study employs a content analysis approach to investigate usage of CCP strategies and symbols across different consumer culture positioning (CCP) strategies, countries and products categories. We focus on country of origin (COO) cues as symbols of CCP. We collect and content analyse print ads from countries at different levels of economic development and communication orientation, namely Austria $(n=182)$, Hungary $(n=199)$ and Turkey $(\mathrm{n}=120)$, and products with high vs. low involvement levels.

Findings - GCCP and LCCP ads rely more on implicit symbols, while FCCP ads predominantly employ explicit ones. Types of symbols and their utilisation varies across countries and product categories with language, taglines/logos, and brand names being the key component across different ads.

Practical implications - The results document the practices of CCP-based advertising offering important insights on whether and how symbolism can be effectively used for communicating different consumer culture positioning across markets.

Originality - Little is known in terms of how specific symbols are used to communicate consumer culture. In this study we analyse the content of 501 real print ads across multiple countries and product categories. We contribute to theory and practice by revealing how consumer culture manifests through diverse COO symbols in advertising imagery and by facilitating the application of such manifestations across market contexts.
\end{abstract}

Keywords: Consumer culture positioning; Cross-national; Country of origin symbols; International advertising 


\section{Introduction}

Globalization is responsible for the blurring of geographic cultural boundaries through the diffusion of media and the emergence of a global consumer culture (GCC) (Appadurai, 1990; Cleveland and Laroche, 2007; Özsomer, 2019). GCC is manifested via the existence of consumption-bound symbols, signs and behaviours commonly used in advertising of products. Indeed, advertisements operate as signs or narratives that communicate consumer culture associated with the brand itself and its positioning (Alden, Steenkamp, and Batra, 1999). In this sense, advertising cues and other symbols represent important tools for managers to convey intended meaning to audiences. In particular, international advertisers have used such tools to communicate three distinct types of consumer culture positioning (CCP), depending on whether a brand is expressed as a symbol of global consumer culture positioning (GCCP), local consumer culture positioning (LCCP), or a specific foreign consumer culture positioning (FCCP) (Akaka and Alden, 2010; Alden et al., 1999; Halkias et al., 2017). Although current work acknowledges that there may be contextual variance in the usage of CCP strategies (e.g. country, product, symbols, e.g. Taylor and Okazaki, 2015), there is a lack of scholarly research that provides insights into the specific set of symbols that are utilised to convey CCP strategies across national cultures and product categories. Authors corroborate the existence of the gap in the literature, with Czarnecka and Keles (2014) arguing that much of the work on GCCP does not give particular descriptions of its various symbolic manifestations (see also, Westjohn, Singh, and Magnusson, 2012). More recently, Steenkamp (2019) indicates that there is limited research on the managerial applications of global consumer culture, such as the CCP strategies used across countries and product categories. Indeed, although CCP is most likely communicated by advertisers differently across cultures (Alden et al., 1999), the limited number of studies that 
examine representations of consumer culture in advertising typically focus on either a single CCP strategy (GCCP) or a single 'symbol' [appeals, Okazaki, Mueller, and Taylor, 2010] (with the exception of Alden et al., 1999) or product category (Gammoh, Koh, and Okoroafo, 2011), despite research indicating that $\mathrm{CCP}$ is likely to be communicated by advertisers differently across cultures (Alden et al., 1999). Lack of research in this domain has therefore fuelled the inability to understand differences in how consumer culture meaning is transferred through advertising in different national cultures and product contexts; hence treating the development of CCP strategies in a uniform way, inevitably leading to suboptimal ways in communicating consumer culture across different country and product contexts.

Following the aforementioned research gaps, there is a clear need to examine the usage and symbolic manifestation of CCP strategies in advertising across national cultures and product contexts, in order to advance current knowledge on the applications of consumer culture (Steenkamp 2019). This study is therefore novel, and it is guided by two main research objectives: 1) To examine symbols used in advertising to portray CCP strategies, 2) To explore differences in the use of symbols in CCP strategies across national cultures and product categories. To address these objectives, we present a study that provides a comprehensive investigation of how advertisers use CCP strategies across countries with different levels of economic development and communication orientation (e.g., Austria, Hungary and Turkey), and product categories with varying levels of involvement. Additionally, we explore country of origin $(\mathrm{COO})$ cues as symbols of $\mathrm{CCP}$, as to the best of our knowledge they have received minimal research attention, compared to themes and appeals that have been studied to a greater extent in relation to CCP strategies (e.g. Alden et al., 1999; Okazaki et al., 2010). Indeed, despite its importance in affecting international advertising (Akaka and Alden, 2010), less research has 
studied COO as a marketing tool (Roth and Bartsch, 2019), let alone as a CCP advertising tool. Accordingly, the contribution of our study is threefold: Primarily, we offer novel knowledge on the symbolic manifestations of CCP in advertising, thus extending the stream of research that examines applications of consumer culture theory (Steenkamp, 2019). A second contribution involves the examination of COO symbols as tools of CCP strategies, relative to other research that has focused on other symbols such as appeals (e.g. Alden et al., 1999; Czarnecka and Keles 2014), or has not considered COO as a potential CCP tool (e.g., Aichner, 2014; Hornikx et al., 2020; Roth and Bartsch, 2019). Finally, the study provides important practical contributions to international marketers, enhancing the managerial applications of $\mathrm{CCP}$, and thereafter $\mathrm{COO}$ symbols, in international advertising (Samiee, 2011; Steenkamp, 2019). Advertisers should be able to understand how to effectively utilise different CCP strategies (Westjohn et al., 2012) and specific symbols in different country contexts, given that advertising and style of communication varies across countries (Hall, 2000). Our findings contribute to this direction, offering insights to international advertisers regarding simultaneously moving across cultures, standardizing [or not] global messages, and at the same time, increasing the local relevance of products in cultures that do not favour global messages.

\section{Theoretical Background}

\section{Consumer Culture Theory and Cultural Globalization Theory}

The study of consumer culture positioning (CCP) strategies in advertising is underpinned by two main theoretical bases. Initially, consumer culture theory (Arnould and Thompson, 2005) addresses the interrelationship between consumers' behaviours or actions, the marketplace and the cultural meanings that are shared or used by individuals to make sense of their world. Most 
often, cultural meanings are manifested by commercially produced images and symbols, which aim to shape brand evaluations, consumer preferences and attitudes. A second theory underpinning the study of CCP strategies is cultural globalization theory, which focuses on the cross-national transmission of images and symbols, and aims to examine responses to globalism and localism (Pieterse, 2004; Steenkamp, 2019). Akin to this theory is the idea that, individuals respond to market globalization in different ways (see Berry and Sam, 1997; Cleveland and Laroche, 2007). For example, on one hand, individuals may assimilate to a global consumer culture (GCC) manifested via consumption-related symbols (Holton, 2000) enforced by global media (Appadurai, 1990; Walker, 1996), and diffused via the growing number of Englishspeaking audiences (Cleveland et al., 2016). One the other hand, individuals may exhibit a rejection towards globalism and a preference towards local consumer culture (LCC), thus informing cultural positioning strategies. In this case individuals prefer consumption-bound symbols, signs and behaviours that have local connotations, as they help them to keep their unique national identity. These two theories provide the theoretical underpinnings for the development of CCP strategies in advertising.

\section{Consumer Culture Positioning (CCP) Strategies and Country of Origin Symbols}

Consumer culture positioning (CCP) strategies reflect ways in which advertisers leverage consumer culture in their communication content (e.g. global, foreign or local) (Huang and He, 2019). Alden et al. (1999) proposed global consumer culture positioning (GCCP) as a strategy that enhances a brand's globalness and affects purchase behaviour. Twenty years later, Steenkamp (2019) adds that GCCP reflects the brand as being “... consumed by globally recognised celebrities or people from any or all cultures" (p. 27). GCCP is based on the rationale 
that a global consumer culture exists, which encompasses a set of shared consumption-related symbols in the form of products, brands, behaviours that are recognised and are important to people all over the world (Cayla and Arnould, 2008; Keillor, D'Amico and Horton, 2001; Terpstra and Kenneth, 1991). GCCP as a strategy has been contrasted with other CCP strategies namely, foreign customer culture positioning (FCCP) and local customer culture positioning (LCCP) (Alden et al., 1999; Halkias et al., 2017; Nijssen and Douglas, 2011). FCCP denotes a positioning strategy where the brand symbolically reflects a particular foreign consumer culture, while LCCP attempts to connect the brand with meanings and symbols that indicate the norms and identity of the local culture (Alden et al., 1999).

CCP strategies are manifested in advertising via the use of various symbols, though the level of their utilisation within each specific strategy is likely to differ. Research compares advertising appeals as tools of CCP strategy focusing mostly on GCCP (e.g. Czarnecka and Keles, 2014; Okazaki et al., 2010). For example, based on Pollay's list of appeals, Czarnecka and Keles (2014) propose a framework of twelve advertising appeals representing GCCP, including appeals such as effective, durable, convenient, freedom, enjoyment, and wisdom. Despite its key role in influencing product evaluations and purchase decisions, less research has been devoted to country of origin (COO) as an advertising and CCP tool (e.g. Hornikx et al., 2020; Roth and Bartsch, 2019). COO refers to the image consumers hold for the origin of a product (for a review of COO please see Lu et al., 2016). The concept has been previously linked to global brands (e.g., Halkias, Davettas and Diamantopoulos, 2016; Pharr, 2005; Zhou and Belk, 2004), with authors suggesting that $\mathrm{COO}$ cues can be successfully used to symbolically communicate consumer culture in advertising (Aichner, 2014; Herz and Diamantopoulos, 2013; Melnyk, Klein and Völckner, 2012). More specifically, explicit COO symbols, such as country of origin labels (e.g. 
domestic/local origin, foreign or global whereby a brand has a non-domestic origin and it is recognised globally, Salnikova and Grunert, 2020), flags and maps can be utilised to signify a relationship with a specific culture, group or team (Moriarty, 2004), and are typically used in international advertising (e.g. Roth and Bartsch, 2019). Such symbols constitute tools to communicate consumer culture and they may be used for GCCP, LCCP or FCCP strategy (Aichner, 2014). Additionally, CCP strategies can be explicitly reflected via quality information (in this case, labels which indicate 'quality' that links to a specific country e.g., Greek-style yogurt, thus using a FCCP strategy), as well as $\mathrm{COO}$ embedded within the company/brand name (e.g. American Apparel; Swiss Army). On the other hand, implicit COO symbols can be used to visually and indirectly express the advertising message, thus reflecting key cultural significations and traditions linked to different CCP strategies (e.g. GCCP, LCCP or FCCP) (Petrovici, 2013). Such symbols constitute language (local language or English for GCCP) (Hornikx and van Meurs, 2019; Hornikx et al., 2020), stereotypical people (locally or globally-known celebrities) and landscapes (e.g. using either local landscapes which link to national identity, or globallyrecognised landscapes e.g., Steenkamp, 2019), brand logos (Alden et al., 1999) and slogans that imply a global or a local connection (Coca Cola: Think local, Act local had a distinct British feel, Bainbridge, 2001) and famous buildings and monuments (e.g. Eiffel Tower, London Bridge, Statue of Liberty) ${ }^{1}$ (Aichner, 2014; Roth and Bartsch, 2019). Nevertheless, research which examines the usage of the different aforementioned $\mathrm{COO}$ symbols within $\mathrm{CCP}$ strategies by international advertisers is almost non-existent. The limited research which exists posits that GCCP may be more commonly manifested via implicit imagery elements (e.g., Akaka and Alden, 2010; Alden et al., 1999; Chao and Arnold, 2005; Nijssen and Douglas, 2011; Steenkamp, 2019),

\footnotetext{
${ }^{1}$ It should be noted that some Western monuments, such as the Statue of Liberty, have a more global than local status.
} 
relative to the other CCP strategies. This is because implicit elements are more adaptable and suitable for cultural globalization (Okazaki et al., 2010), relative to explicit ones. Drawing on this rationale, we argue that:

H1: GCCP ads will use more implicit COO symbols compared to a) LCCP and b) FCCP $a d s$

\section{Cross-National Differences in Consumer Culture Positioning (CCP) Strategies in Advertising}

Communication content is influenced by the context in which it is created (Kates and Goh, 2003), with variations in the usage of consumer culture elements being expected across countries. Such variations are examined at an individual or national level (Özsomer, 2012), with prior research focusing on characteristics such as cosmopolitanism and ethnocentrism or culture and level of economic development, respectively (e.g., Alden et al., 1999; An, 2007; Czarnecka and Keles, 2014; Czarnecka, Brennan and Keles, 2018; Guo, 2013; Sobh et al., 2018). Using a country-level lens, both early and more recent research (Alden et al., 1999; Czarnecka et al., 2018) identifies differences in the use of strategies to convey CCP (e.g. GCCP) in advertising, suggesting that GCCP maybe more effective in developing countries compared to developed countries. This parallels research on $\mathrm{COO}$ and brand globalness, which posits that brands positioned with global symbols and connotations are associated with higher status and performance (Alden and Batra, 2003; Steenkamp et al., 2003 etc.), and can be particularly attractive to consumers in developing countries (Jin et al., 2015). However, compared to developing countries, modern developed economies (such as countries belonging to the EU) are characterised by a greater diffusion of globalization as a result of higher exposure to digital and 
global mass media, which fosters openness to global consumer culture (e.g. Cleveland and Bartsch, 2019; Cleveland and Laroche, 2007; Makri, Papadas, and Schlegelmilch, 2019;

Özsomer, 2019). This feeds the development of 'global' consumer segments whereby consumers develop similar understanding of global brands and interpret symbols depicted in advertising in a similar manner (e.g. Brand slogans) (Özsomer, 2012; Strizhakova, Coulter and Price, 2008). The level of economic development of a country may therefore shape managers' decision making with regard to the usage of positioning strategies (e.g. GCCP) in advertising. We expect that, contrary to developing countries, developed countries will use more GCCP, as a result of higher of levels of globalization.

H2a: Developed countries will use more GCCP while developing countries will use more $L C C P$ and FCCP

Moreover, advertising messages are created based on expectations about how audiences (e.g., within a country) are likely to respond (Scott, 1994), thus informing international advertising strategy. The cultural values and orientations of specific audiences determine their acceptance of, and/or openness to, global consumer culture at a national level (Özsomer, 2012; Steenkamp and de Jong, 2010), and shape how advertising is executed by managers across countries in terms of how creative cues and symbols are used, including COO symbols (Callow and Schiffman, 2002; Gürhan-Canli and Maheswaran, 2000; Hornikx and le Pair, 2017; Insch and McBride, 2004; LaRoche et al., 2003; Liu and Johnson, 2005; Roth and Bartsch, 2019). In a recent study comparing advertising between countries, Roth and Bartsch (2019) found that French advertisements used COO to a lesser extent, vis-a-vis to Indian advertisements. 
Moreover, research has used cultural dimensions (e.g. Hofstede, GLOBE) to explain variations in the use of CCP symbols in advertising across countries (Czarnecka et al., 2018; Okazaki et al., 2010). In particular, Hall's (2000) communication context theory explains national differences in preferences for implicit vs. explicit symbols in advertising (Hornikx and le Pair, 2017), whereby in high context cultures (e.g., Eastern, and Asian countries) messages are communicated in an indirect, implicit way, as opposed to low communication context cultures that prefer direct and explicit communication (An, 2007). CCP advertising strategies in high context countries may therefore likely to include more imagery/implicit COO symbols. On the other hand, low context countries (e.g., Western countries) are likely to prefer more direct approaches in CCP in advertising with the use of more explicit symbols (Taylor and Okazaki, 2015). On the basis of the above discussion, we hypothesise:

H2b: In low-context countries ads will employ more explicit COO symbols, while in highcontext countries ads will employ more implicit COO symbols in CCP strategies

Moreover, CCP symbolism can vary depending on the nature of the product category (Huang and He, 2019). For instance, it is observed that GCCP is used more for advertising durable, high involvement, high-technology products as opposed to food or low involvement products, where LCCP is most preferred by advertisers (Alden et al., 1999). Additionally, the number and types of symbols, including $\mathrm{COO}$ symbols, used to advertise products differ based on consumers' involvement in a product category (Roth and Bartsch, 2019). Notably, the level of involvement individuals attach to a product class (Michaelidou and Dibb, 2008) has been used to categorise products in relation to motives and consumers' responses to advertising content (e.g. 
hierarchy of effects) (Vaughn, 1980). Advertising for high involvement products, such as cars, triggers a more elaborate thinking and evaluation process, whereby such products are suitably advertised via cognitive, information-based cues. In this case, explicit symbols such as origin and company information/brand may play a key role in international advertising of high involvement products (e.g. cars such as BMW, Volvo etc), serving as evaluative cues to denote product quality and benefits (e.g. safety) (Verlegh and Steenkamp, 1999). On the contrary, low involvement products (e.g. food) that entail less effort in information processing and evaluation, require more affective, image-based cues in their advertising, such as $\mathrm{COO}$ implicit cues (spokespeople, landscapes, slogans etc). Product categorisations may therefore determine the use of specific symbols and cultural positioning of products in advertising (Czarnecka and Keles, 2014). Additionally, high involvement and durables products (e.g. mobile phones, cars, electrical appliances) are likely to reflect global brands and consumer culture (Alden et al., 1999), while low involvement products (non-durables, such as food and clothing) are said to link better to local cultural connotations and people. Therefore, the way products are symbolically positioned in advertising to reflect consumer culture, in terms of CCP strategy and COO symbols, is expected to vary on the basis of the level of involvement they invoke. Thus:

H3: High involvement products will employ more GCCP strategies, relative to lowinvolvement products which will employ more a) LCCP and b) FCCP strategies H4: High-involvement products will employ more explicit COO symbols in CCP strategies, while low-involvement products will employ more implicit symbols in CCP strategies 


\section{Methodology}

Content analysis was used to address the aims of the study, in line with previous research (Alden et al., 1999; Czarnecka and Keles, 2014; Mueller, 1996; Okazaki et al., 2010). As a method, content analysis identifies and categorises media content into coding categories, in order to understand their contextual use (Hsieh and Shannon, 2005). This approach is advantageous as it is deemed 'unobtrusive and nonreactive', enabling the researchers to gain insights about the contextual use of specific codes within content (Babbie and Mouton, 1992; Hsieh and Shannon, 2005). We collected data in the form of printed magazine advertisements from seven product categories, and three countries namely, Austria $(n=182)$, Hungary $(n=199)$ and Turkey $(n=$ 120). We focused on advertisements from product categories, with varying levels of involvement such as: cars, high-technology durables, jewellery and watches, personal non-durables, nonalcoholic beverages, alcoholic drinks, and clothing. The product categories were assigned into either high- or low-involvement category by the researchers, in line with previous approaches (Alden et al., 1999; Mueller, 1996), and were equally represented in the advertising content in all three countries. In terms of selection criteria, the advertisements were selected from a population of advertisements in magazines (e.g., Elle, Maxima, Cosmopolitan, Elle Turkiye; Wienerin, Miss, In Style, etc) and newspapers with nationwide coverage and high readership ratings (e.g., Roth and Bartsch, 2019). We focused on media outlets of general appeal (non-thematic), and comparable across the three countries in terms of general format and editorial content. Consistent with Alden et al. (1999) we excluded from the sample advertisements that: (a) were repeated or referred to previous advertisements, (b) belonged to local advertising (e.g. advertising for small, local retailers), and (c) consisted of sales promotions.

The selection of the countries was based on (a) level of economic development (e.g. UN, 
2014) and (b) communication orientation (Hall 2000), which allow us to identify differences in the execution of $\mathrm{CCP}$ strategies and usage of $\mathrm{COO}$ symbols in advertising across the three countries. First, there is considerable variation in the economic development across Austria, Hungary and Turkey (in terms of GDP per capita) (Statistictime, 2018; Worldometer, 2019). Austria and Hungary are neighboring countries, are both classed as developed countries with similar political systems and are both members of the European Union. However, Austria is regarded as a well-developed country with a much higher GDP (455.3 billion USD) compared to Hungary (GDP: 157.9 billion USD) which has transitioned into a market economy fairly recently, and has considerably less per capita income compared to the EU average (Indexmundi, 2020). Additionally, Austria has a bigger advertising industry (advertising spend over $\$ 4$ billion, in 2018) compared to Hungary (advertising spend: $\$ 1$ billion). On the other hand, Turkey is classified as a developing nation, and has a higher population and a larger GDP (743.4 billion USD) but relatively smaller advertising industry compared to Austria and Hungary (in terms of ad spend: just over a billion USD) (e-marketer, 2018; Statista, 2018). Second, in terms of communication context, prior research positions Austria as a low-context communication country, while Turkey and Hungary are seen as high-context communication countries (Chwiałkowska, 2012; Haghirian, 2010; Holicza, 2016).

\section{Analysis and Findings}

We developed an 'a priori' coding scheme based on existing literature (Aichner, 2014; Akaka an Alden, 2010; Alden et al., 1999; Roth and Bartsch, 2019; Salnikova and Grunert, 2020), albeit considering the objectives of the study (Table 1). The coding scheme was then applied to identify how advertisers use $\mathrm{CCP}$ strategies and $\mathrm{COO}$ symbols in different countries and product 
categories using the sample of advertisements collected from the three countries (Hsieh and Shannon, 2005; Poole and Folger, 1981). Six researchers from the three different countries coded and analysed the advertisements for the sample of their own country independently. To ensure reliability of the procedure (Kolbe and Burnett, 1991; Weber, 1990), inter-coder reliability was calculated using a random sample $(n=60)$ of advertisements $(20$ per country), which were not part of the main sample of advertisements. Inter-coder agreement was assessed via Cohen's Kappa, with values being high and acceptable for all three countries (Austria $=0.80$; Hungary 0.82; Turkey $=0.79$ ), thus indicating good reliability (Stemler, 2001). During the analytical procedure, the researchers systematically identified occurrences of symbols, categorised them, and contextualised their occurrences in three levels: in terms of CCP strategy, country, and product category (Table I). In line with the coding scheme, frequencies for each distinct symbol were calculated in the levels which they occurred. In doing so, researchers also indicated whether the symbols reflected a combination or hybrid CCP strategy (Alden, Steenkamp, and Batra, 2006) (LCCP/FCCP, LCCP/GCCP).

Table I here.

In line with the study's research objectives, we analyse symbols within CCP ad strategies, and how these differ across the three countries and product categories. The results show a total of 1957 occurrences of COO symbols in the advertisements under investigation, with $41.6 \%$ of symbol occurrences observed within GCCP strategy, followed by LCCP (29.5\%), and FCCP (16.1\%) suggesting that COO cues are indeed seen as a useful elements by advertisers to communicate consumer culture and especially GCCP. The findings also indicate that FCCP 
strategy uses mostly explicit COO symbols (75\%), such as origin and brand/company name, as opposed to implicit COO symbols $(z=8.853, \mathrm{p}<0.001)$. Conversely, GCCP and LCCP strategies use more implicit than explicit symbols $\left(z_{-}{ }_{\mathrm{GCCP}}=7.231, \mathrm{p}<0.001\right.$ and $z_{-} \mathrm{LCCP}=9.673$, $p<0.001)$ though there are key variations between them in terms of the type of implicit symbol used to convey each positioning strategy. More specifically, within the different types of implicit symbols, we find that GCCP and FCCP ads employ more slogans and taglines (GCCP: $\chi^{2}(3)=$ 58.356, $p<0.001$ and FCCP: $\left.\chi^{2}(3)=30.418, p<0.001\right)$, whereas in LCCP ads the use of language is clearly the dominant element to convey 'localness' $\left(\chi^{2}(3)=330.101, p<0.001\right)$ (Table II).

Table II here.

Furthermore, findings indicate variations in CCP ads strategies across the three countries, as well the presence of specific symbols within the CCP strategies and countries (Table III). Although not the same, advertising practices in the two developed countries seem to converge, while CCP ad strategies in developing Turkey follow a different pattern. We find that ads from Austria and Hungary use more GCCP (45.3\% and 50.5\%, respectively) compared to Turkey (24.9\%). On the contrary, advertising in Turkey uses more LCCP (45.1\%) with more implicit symbols. We also observe variations and similarities in the specific symbols used across the three countries. For instance, 'origin' is the least used explicit symbol in CCP strategies across all three countries. Interestingly, we find no occurrences of origin in GCCP in the advertising sample from Turkey. In terms of implicit symbols, we find that language is the most used symbol for LCCP strategy in all three countries, while 'slogans/taglines' are used more in GCCP 
strategy in Austria and Hungary compared to Turkey, that relies more language in CCP strategies. Finally, we observe that landscapes and monuments is the least used implicit symbol in all three CCP ad strategies (6.2\%), and countries (see Table 3).

Table III here.

\section{Hypotheses testing}

We conducted a series of chi square tests to test our hypotheses. The results provide support for H1b $\left(\chi^{2}(1)=218.80, \mathrm{p}<0.001\right)$ but not H1a $\left(\chi^{2}(1)=1.632, \mathrm{p}=0.20\right)$, indicating that GCCP uses more implicit COO symbols relative to FCCP, but not relative to LCCP. These results contradict prior research (Alden et al., 1999; Okazaki et al., 2010) that suggests that GCCP generally uses more image-based symbols relative to LCCP. Furthermore, investigating the type of implicit symbols revealed that language dominates LCCP ad development (43.45\%), whereas slogans/taglines and logos are most prominent in GCCP and FCCP ads with $35.2 \%$ and $12.6 \%$, respectively (in the latter case, though, implicit symbolism only accounts for $1 / 4$ of all $\mathrm{COO}$ cues identified). Furthermore, we find partial support in terms of H2a. More specifically, we find a higher proportion of GCCP ads in Hungary and Austria (Hungary $=50.6 \%$ vs. Austria $\left.=45.4 \% ; \chi^{2}(1)=3.825, \mathrm{p}=0.51\right)$ and a significantly lower proportion Turkey $(24.9 \%$; proportion differences with Hungary and Austria significant at $\alpha=.01$ ). LCCP ad strategies are more common in Turkey $($ Turkey $=45.2 \%$, Hungary $=17.8 \%$, Austria $=30.2 \%$; all proportion differences significant at $\alpha=.01$ ). However, the two developed countries show significant differences in terms of LCCP, with Hungary having fewer LCCP ads compared to Austria. With reference to FCCP usage, it seems that such ads are equally common in Turkey and Hungary (no 
significant differences), while far more common in relation to Austria (11.1\% proportion differences with Hungary and Turkey significant at $\alpha=.01$ ). This similarity in the use of FCCP between Hungary and Turkey may be attributed to the exact stage of Hungary's economic development; while it is classed as developed, it represents a more recently-transitioned market economy relative to other well developed countries.

Moreover, we find no significant differences between Austria and Hungary in the overall use of explicit and implicit symbols in CCP strategies. However, we uncover significant differences between countries within specific CCP strategies, thus providing partial support to H2b. First, in comparing ads from Austria and Hungary in terms of symbols within specific CCP strategies, we find that both countries use similar symbols in GCCP in spite of the fact that they are different in terms of communication orientation (e.g. Hall, 2000). Our results also show significant differences in the opposite direction, with ads from Austria having more implicit and explicit symbols in LCCP relative to that from Hungary $\left(\chi^{2}(1)=10.69, p<0.001\right)$. However, a closer look reveals variations in the use of specific types of implicit symbols between Austria and Hungary. More specifically, we find that a) Austrian and Hungarian ads differ in terms of language and landscapes/monuments used to convey $\operatorname{GCCP}\left(\chi^{2}(1)=4.20, p<0.001\right)$, and $\left.b\right)$ in terms of origin and brand/company information used to convey $\operatorname{LCCP}\left(\chi^{2}(1)=3.54, p<0.05\right)$.

Second, in comparing Austria and Turkey, we find that the use of both implicit and explicit symbols in GCCP strategy is higher in Austria compared to Turkey $\left(\chi^{2}(1)=26.76, p<\right.$ 0.001), while there are no differences between Austria and Turkey in the use of implicit and explicit symbols in LCCP strategy $\left(\chi^{2}(1)=2.20, p<0.13\right)$. However, a comparison in terms of specific symbols used in LCCP between the two countries shows significant differences in the use of language and slogans to convey LCCP $\left(\chi^{2}(1)=4.048, p<0.05\right)$; with Austria using 
more language in LCCP and Turkey using more slogans/logos and taglines in LCCP. In terms of hybrid CCP strategy, we find significant differences in the use of symbols between Austria and Hungary $\left(\chi^{2}(1)=4.55, p<0.05\right)$, with Hungary using more implicit symbols in hybrid CCP strategy, relative to Austria; Austria on the other hand uses more relative to Turkey $\left(\chi^{2}(1)=\right.$ $10.36, \mathrm{p}<0.01)$.

Finally, we find no significant results for H3a $\left(\chi^{2}(1)=0.017, p<0.89\right)$, however we find support for $\mathrm{H} 3 \mathrm{~b}\left(\chi^{2}(1)=13.203, \mathrm{p}<0.001\right)$, indicating that high involvement products use more GCCP relative to FCCP. Indeed, we find 443 occurrences of GCCP ads in high involvement products relative to 196 occurrences in FCCP (Table IV). This result suggests that high involvement products are positioned as more global than foreign in advertising in the three countries studied. . Finally, we find no support for H4 positing that high involvement products use more explicit symbols, compared to low involvement products. Table 4 indicates that occurrences of explicit symbols in advertising is equivalent between high (34.4\%) vs. low (37.2\%) involvement products. However, further chi square tests show that high and low involvement products differ in the use of explicit symbols within CCP strategies. More specifically, when we compare high and low involvement products in terms of symbols in a) LCCP and b) GCCP strategies, we find significant differences in the use of origin and brand information (LCCP: $\left.\chi^{2}(1)=4.29, p<0.05\right)$ and GCCP: $\left.\chi^{2}(1)=5.70, p<0.05\right)$. Ads for high involvement products use marginally more origin symbols, relative to low involvement, which uses more brand/company information, in both LCCP and GCCP. Additionally, we find significant differences in the use of stereotypical people and landscapes/monuments in GCCP $\left(\chi^{2}\right.$ $(1)=25.800, p<0.001$ ), between high and low involvement products, with high involvement products using more landscapes, while low involvement counterparts use more stereotypical 
people in their advertising.

Table IV here.

\section{Discussion, Implications and Limitations}

In this study we set out to examine how advertisers communicate consumer culture via CCP strategies and symbols. Specifically, we focused on a) whether and b) how symbols are used in international advertising to communicate various CCP strategies in three different countries with varying economic development levels as well as communication orientation (Austria, Hungary and Turkey) and across high and low involvement product categories. Our findings offer interesting theoretical and managerial implications. First of all, this study fills research gaps in the current knowledge pertaining to the application of consumer culture theory (e.g. Steenkamp, 2019) by identifying how specific symbols are used within CCP strategies in advertising in different countries and product categories. We focused on COO symbols, and at the general level, our results show that such symbols are used mostly within GCCP strategy highlighting their effectiveness as a tool to convey global consumer culture. We find that both GCCP and LCCP ads use mainly implicit COO symbols, while advertisers tend to use explicit symbols, such as an origin label or company name, to convey FCCP. These findings corroborate prior research suggesting that implicit symbols may be more useful for GCCP (Akaka and Alden, 2010) relative to other CCP strategies as they more adaptable to globalization.

Our findings contribute to relevant research by suggesting that implicit symbols are highly useful for conveying LCCP strategy. While this result is unexpected, the reason behind it might be found in the type of implicit symbol mostly used to convey LCCP strategy, namely 
language. Compared to GCCP ad approaches, where $\mathrm{COO}$ symbols such as slogans, taglines and logos are used the most (35.2\%), language (e.g. Hungarian, German and Turkish) is mostly used to forge connections with the local culture. While English language is very often used in advertising to reflect GCCP (Alden et al., 1999; Cleveland and Laroche, 2007; Gammoh et al., 2011), we find that language is mostly used as a local symbol (43\%) relative to a global (11.3\%) or a foreign one (5\%). Given the wide diffusion of English language across the globe and people's familiarity with English, it appears that language, as a creative element, is relatively stronger in inducing the notion of localness and weaker in evoking a global consumer culture. Taking into account the crucial role of language in defining and maintain national heritage and culture (Rosa, Sillani, and Vasciaveo, 2017), it is not surprising that advertisers often utilise this cue to come closer to local societies. Interestingly, language is the most utilised symbol in hybrid strategy (Alden et al., 2006) in general, and across all three countries. Research exploring the effects of dual language usage in product packaging argues that bilingual product information might not be judged favourably as it provides legitimacy to the out-group ("the other language group") (Gopinath and Glassman, 2008). Hence, the question that remains and calls for future research endeavours is whether the use of language as a $\mathrm{COO}$ cue to portray a hybrid CCP strategy is indeed successful and under which conditions.

Second, as our study looks into developed and developing countries with diverse communication orientations, the results enable us to better understand cross-national applications of consumer culture theory (Steenkamp, 2019), and at the same time they challenge the current knowledge on the use of $\mathrm{COO}$ symbols across cultures and product categories. Indeed, an interesting contribution of our study is that it challenges current knowledge on the use of GCCP strategies in developing economies. Previous research indicates that developing countries tend to 
use more GCCP in their advertising, while less GCCP appears in the advertising of developed countries, attributing the differences largely on cultural dimensions (Czarnecka et al., 2018). Our results show that it is in fact the developed economies that reach out towards this strategy in their communication efforts compared to the developing country in our sample. This is explained by the fact that, relative to Turkey that uses less GCCP, both Austria and Hungary are developed countries, and Schengen members of the European Union. Developed countries allow for a greater diffusion of globalization, whereby consumers become acculturated as societies are exposed to more globally-positioned brand advertising (Cleveland and Laroche 2007). At the same time advertisers across EU countries follow advertising standards and EU legislation (Easa; European Commission), though in the case of CCP both domestic and foreign brands can use CCP strategies (Liu, Tao, and Tsai, 2017). On the contrary, Turkey is a middle-eastern country with controlled-access to digital mass media (Reuters, 2019) that impacts on the diffusion of global consumer culture, hence advertisers focus more using LCCP and FCCP. Also Turkish consumers are more ethnocentric (e.g., Acikdill, Ziemnowicz and Bahhouth, 2018), compared to Hungarians, thus products (even global brands) promoted in Turkey ought to link to local culture and tastes.

With regards to the use of COO symbols across countries, the results show similar patterns as those of CCP strategies between Austria and Hungary; even though the two countries differ in their level of communication orientation (Hall, 2000). As a low-context country, we expected Austria to use more explicit symbols, as opposed to Hungary and Turkey. This is true only in the case of hybrid strategy, whereby we find that Hungary as a high-context country uses overall more implicit symbols relative to Austria. On the contrary, we find that both Austria and Hungary use implicit symbols in their GCCP relative to Turkey. However, variations are 
observed in the types of implicit symbols used in GCCP between the two developed countries (Austria and Hungary). For instance, more landscapes and monument symbols (10\%) are utilised in Hungarian advertising relative to Austrian (6.3\%) advertising to convey GCCP, while Austrian advertising uses language (14.4\%) to a greater extent to convey GCCP. Such variations may be attributed to the different communication contexts. For example, while language and landscapes and monuments are both implicit symbols, they differ in their execution in advertising, with language being written and landscapes and monuments being visual. The fact that Austrian ads use language to a greater extent to convey GCCP relative to Hungary, may imply that language is used as a 'direct' COO symbol in the context of conveying CCPs. This also raises the question of whether language can operate as both implicit and explicit symbol depending on the given country context.

Moreover, our results indicate variations in the use of CCP strategies within high and low involvement product categories. Prior research supports that high involvement durable products are mostly reflected by GCCP in advertising (e.g. Alden et al., 1999). However in our study we also find that this is true for low involvement product categories as well. Additionally, our results show that both categories of products use mostly implicit symbols, relative to explicit ones, to convey CCP strategies in advertising. Initially, and extending recent research (Roth and Bartsch, 2019), we find that high involvement products (such as durable, technology products) use more COO symbols in their CCP strategies overall, relative to low involvement products (e.g. food). This is because advertising of high involvement products triggers a higher level of processing and elaboration which requires a greater number of cues (Vaughn, 1980). Finally, and relating to specific CCP strategies, our results corroborate that, both high and low involvement products use more implicit $\mathrm{COO}$ symbols in their $\mathrm{CCP}$ advertising. Specifically, more slogans and taglines are 
used to convey GCCP, reflecting a product's globalness (e.g. Grey goose: World' best tasting Vodka), while LCCP relies more on language as a COO symbol. In this instance, language seems to help portray a connection with a local culture (Rosa et al., 2017), irrespective of whether individuals see the products as personally important or relevant to them. Interestingly, (and contrary to hypothesis H3a), we find that GCCP is the most utilised strategy in the advertising of both categories followed by LCCP, however the products differ in terms of the use of implicit symbols (stereotypical people, landscapes and monuments) in GCCP and explicit symbols (e.g. origin, brand/name) in both GCCP and LCCP. Finally, the findings indicate the symbols' occurrences within GCCP is more widespread (e.g. slogan, famous/stereotypical people, story themes etc.) as opposed to the symbols used to portray a LCCP strategy (predominantly portrayed via "use of language") or and FCCP strategy (predominantly portrayed via brand/company name) strategy, indicating that $\mathrm{COO}$ is an effective practical tool for GCCP (e.g. Samiee, 2011). 


\section{Managerial Implications}

In terms of managerial implications, the results of the present study are relevant for international marketing professionals wishing to position their brands in countries with differing levels of economic development and communication orientation. First, our study shows that a COO typology of symbols (Aichner, 2014) can be used to a greater or a lesser extent to portray an intended CCP strategy by international advertisers. We also show that certain $\mathrm{COO}$ symbols that are indicated as good manifestations of GCCP, are not dominantly used in everyday marketing practice. For example, 'origin' is surprisingly absent or used rarely in print advertisements in all three countries, suggesting that it is not an effective $\mathrm{COO}$ tool to convey CCP strategies. Furthermore, given the importance of implicit symbols for both LCCP and GCCP, in all three countries, advertisers could consider standardizing advertisements in magazines on these specific symbols. On the other hand, our results provide a list of symbols used to portray a GCCP strategy and show that the same symbols can be used in both high and low context, developed and less developed countries; unlike other research which has, so far, provided insufficient findings regarding different types of symbols used for CCP in advertising. However, the way these symbols are used differs at the country and at the product category levels, where variations can be observed in the occurrences of specific symbols within CCP strategies. Therefore, relative to extant research, our findings are more useful to managers as we identify specific symbols that can be used to convey all three CCP strategies. Additionally, the identification of variations in the usage of specific and varied symbols across CCPs, countries and product categories, provides a set of insights or 'lessons' for international advertisers; in that GCCP with similar symbols may be achieved at a regional level, as opposed to global level; given that the majority of research has focused on a single symbol (e.g. appeals) and in countries 
with extreme cultural peculiarities (e.g. US, Japan etc.) (Onkvisit and Shaw, 1999). Additionally, our findings indicate that GCCP can be manifested by more implicit symbols for both high and low involvement products, though when it comes to different strategies there are some variations within CCP strategies and countries. As such, international advertisers' can achieve standardisation when it comes to GCCP and the symbols used, whereas adaptation is required for LCCP with particular emphasis on the role of language in high context countries, relative to low context countries, where additional implicit symbols may be used to reflect LCCP.

\section{Limitations and directions for future research}

Reflecting on our study, there is a number of limitations we need to acknowledge. Initially, while we used a thorough list of symbols to explore occurrences within CCP strategies, more insights are required into the use of language as a CCP symbol. More specifically, English language has been claimed to be the symbol of globalism and hence a tool for portraying a GCCP communication strategy (Akaka and Alden, 2010). However, it might be that today's consumers have become used to the idea of seeing and hearing the English language in advertisements and hence English as a language cue might have 'exhausted' its power to portray a GCCP strategy. In addition, we analysed advertisements from a German speaking country and two other countries with a language that is solely spoken in one country (i.e. Hungarian, Turkish). It might be that the local language in Austrian advertisements could actually be a symbol of a FCCP (products coming from Germany or Swiss products). Hence, in general, language is a symbol and its ability to portray CCPs warrants further research. Furthermore, we have focused one-sidedly on the advertisers and investigated their application of symbols to portray a particular culture positioning with a conclusion that a GCCP strategy dominates as a 
communication strategy in Austria and Hungary, while FCCP is used in Turkey. Further research is required to include consumers' responses to such advertisements capturing individual variables such as ethnocentrism and cosmopolitanism (Öszomer, 2012), and to uncover whether there is a gap between advertisers' conviction of the CCPs they are portraying and symbols they use to achieve this and consumers' perceptions of these advertisements. Finally, the current work provides a substantive focus on identifying $\mathrm{COO}$ symbols as carriers of culture specific meanings. However, this research relied on a single medium, i.e. print advertisements and a product-category level comparison. Future research should determine the potential for generalisability of the study findings across different media contexts, but also across different types of brands (e.g. luxury vs. non luxury brands). For example, statistics show that the most used medium throughout the countries in Europe is television, with social networks and the internet becoming increasingly important as well (Statista, 2017). 


\section{References}

Acikdilli, G., Ziemnowicz, C., and Bahhouth, V. (2018), “Consumer ethnocentrism in Turkey: Ours are better than theirs", Journal of International Consumer Marketing, Vol. 30 No. 1, pp. 45-57.

Aichner, T. (2014), “Country-of-origin marketing: A list of typical strategies with examples”, Journal of Brand Management, Vol. 21 No. 1, pp. 81-93.

Akaka, M. A. and Alden, D. L. (2010), “Global brand positioning and perceptions: International advertising and global consumer culture", International journal of Advertising, Vol. 29 No. 1, pp. 37-56.

Alden, D. L., Steenkamp, J. B. E. and Batra, R. (1999), "Brand positioning through advertising in Asia, North America, and Europe: The role of global consumer culture", The Journal of Marketing, Vol. 63 No. 1, pp.75-87.

Alden, D.L., Steenkamp, J.B. and Batra, R. (2006), “Consumer attitudes toward marketplace globalization: structure, antecedents and consequences", International Journal of Research in Marketing, Vol. 23 No. 3, pp. 227-239.

An, D. (2007). Advertising visuals in global brands' local websites: a six-country comparison. International Journal of Advertising, Vol. 26 No. 3, pp. 303-332.

Appadurai, A. (1990), "Disjuncture and difference in the global cultural economy", Theory, culture \& society, Vol. 7 No. 2-3, pp. 295-310.

Arnould, E. J., and Thompson, C. J. (2005), “Consumer culture theory (CCT): Twenty years of research", Journal of consumer research, Vol. 31 No. 4, pp. 868-882.

Babbie, E., and Mouton, J. (1992), The practice of social science, Belmont, CA: Wadvertisementsworth. 
Berry, J. W., and Sam, D. L. (1997), “Acculturation and adaptation”, Handbook of cross-cultural psychology, Vol. 3 No. 2, pp. 291-326.Berry, J.W., Kim, U., Power, S., Young, M., and Bujaki, M. (1989), “Acculturation attitudes in plural societies”, Applied Psychology, Vol. 38 No. 2, pp. 185-206.

Callow, M. and Schiffman, L., (2002), "Implicit meaning in visual print advertisements: a crosscultural examination of the contextual communication effect", International Journal of Advertising, Vol. 21, No. 2, pp.259-277.

Cayla, J., and Arnould, E. J. (2008), “A cultural approach to branding in the global marketplace”, Journal of International Marketing, Vol. 16 No. 4, pp. 86-112.

Chao, M. C. H., and Arnold, M. J. (2005), "Exploring the Practical Effects of Country of Origin, Animosity, and Price-Quality", Journal of International Marketing, Vol. 13, No. 2, pp. 114150.

Chwiałkowska, A., (2012), “Teamwork in a cross-cultural context. Austria, Poland and Turkey comparison", Journal of Positive Management, Vol. 3 No. 1, pp.33-49.

Cleveland, M. and Bartsch, F. (2019), "Global consumer culture: epistemology and ontology", International Marketing Review, Vol. 36 No. 4, pp. 556-580.

Cleveland, M., and Laroche, M. (2007), “Acculturation to the global consumer culture: Scale development and research paradigm", Journal of business research, Vol. 60 No. 3, pp. 249259.

Cleveland, M., Rojas-Méndez, J. I., Laroche, M., and Papadopoulos, N. (2016), “Identity, culture, dispositions and behaviour: A cross-national examination of globalization and culture change”, Journal of Business Research, Vol. 69 No. 3, pp. 1090-1102.

Czarnecka, B. and Keles, S. (2014), "Global Consumer Culture Positioning: the use of Global 
Consumer Culture Positioning appeals across four European countries", Journal of Euromarketing, Vol. 23 No. 3, pp. 59-67.

Czarnecka, B., Brennan, R., and Keles, S. (2018), "Cultural Meaning, Advertising, and National Culture: A Four-Country Study“, Journal of Global Marketing, Vol. 31 No. 1, pp. 4-17.

EASA, The European Advertising Standards Alliance, available at: https://www.easaalliance.org/ (accessed 20 $0^{\text {th }}$ May, 2020)

E-marketer (2018), Digital Trends to Watch in 2018, available at: https://www.emarketer.com/content/digital-trends-to-watch-in-2018 (accessed $16^{\text {th }}$ February, 2019)

European Commission, Unfair commercial practices law, available at: https://ec.europa.eu/info/law/law-topic/consumers/unfair-commercial-practices-law en (accessed 20 $0^{\text {th }}$ May, 2020)

Gammoh, B. S., Koh, A. C., and Okoroafo, S. C. (2011), "Consumer culture brand positioning strategies: an experimental investigation", Journal of Product \& Brand Management, Vol. 20 No. 1, pp. $48-57$.

Gopinath, M., and Glassman, M. (2008), “The effect of multiple language product descriptions on product evaluations", Psychology \& Marketing, Vol. 25 No. 3, pp. 233-261.

Guo, X. (2013), "Living in a global world: Influence of consumer global orientation on attitudes toward global brands from developed versus emerging countries", Journal of International Marketing, Vol. 21 No. 1, pp. 1-22.

Gürhan-Canli, Z., and Maheswaran, D. (2000), "Cultural variations in country of origin effects", Journal of Marketing Research, Vol. 37 No. 3, pp. 309-317. 
Haghirian, P. (2010), Multinationals and cross-cultural management: The transfer of knowledge within multinational corporations, Routledge.

Halkias, G., Micevski, M., Diamantopoulos, A., and Milchram, C. (2017), "Exploring the effectiveness of foreign brand communication: Consumer culture ad imagery and brand schema incongruity”, Journal of Business Research, Vol. 80, pp. 210-217.

Halkias, G., Davvetas, V., and Diamantopoulos, A. (2016), “The interplay between country stereotypes and perceived brand globalness/localness as drivers of brand preference", Journal of Business Research, Vol. 69 No. 9, pp. 3621-3628.

Hall, E. T. (2000), “Context and meaning”, In Samovar, L. A. and Porter, R. E. (Eds.), Intercultural communication: A reader, $9^{\text {th }}$ ed., Belmont, CA: Wadvertisementsworth Publishing Co, pp. 34-43.

Herz, M. F., and Diamantopoulos, A. (2013), “Country-specific associations made by consumers: A dual-coding theory perspective", Journal of International Marketing, Vol. 21 No. 3, pp. 95-121.

Holicza, P. (2016), “Understanding Magyar: An Analysis of Hungarian Identity within the Framework of Cultural Dimensions Theory and Additional Metrics", In $4^{\text {th }}$ International Scientific Correspondence Conference, Slovak University of Agriculture in Nitra, pp. 118124.

Holton, R. (2000), "Globalization's cultural consequences", Annals of the American Academy of Political and Social Science, Vol. 570 No. 4, pp. 140-152.

Hornikx, J., van Meurs, F., van den Heuvel, J., and Janssen, A. (2020), "How brands highlight country of origin in magazine advertising: A content analysis", Journal of Global Marketing, Vol. 33 No. 1, pp. 34-45. 
Hornikx, J., and van Meurs, F. (2019), Foreign languages in advertising: Linguistic and marketing perspectives, Springer Nature.

Hornikx, J. and le Pair, R. (2017), "The influence of high-/low-context culture on perceived Ad complexity and liking", Journal of Global Marketing, Vol. 30 No. 4, pp.228-237.

Hornikx, J., van Meurs, F., van den Heuvel, J., and Janssen, A. (2020), “How brands highlight country of origin in magazine advertising: A content analysis“, Journal of Global Marketing, Vol. 33, No. 1, pp. 34-45.

Hsieh, H. F. and Shannon, S. E. (2005), "Three approaches to qualitative content analysis", Qualitative health research, Vol. 15 No. 9, pp. 1277-1288.

Huang, H. and He, J. (2019), "When face meets globalization: How face drives consumers' attitudes towards global consumer culture positioning", International Marketing Review, https://doi.org/10.1108/IMR-01-2019-0031

Indexmundi (2020), “Austria vs. Hungary”, available at:

https://www.indexmundi.com/factbook/compare/austria.hungary/economy (accessed $17^{\text {th }}$ May, 2020)

Insch, G. S. and McBride, J. B. (2004), "The Impact of Country-of-Origin Cues on Consumer Perceptions of Product Quality: A Binational Test of the Decomposed Country-of-Origin Construct", Journal of Business Research, Vol. 57 No. 2, pp. 256-65.

Jin, Z., Lynch, R., Attia, S., Chansarkar, B., Gülsoy, T., Lapoule, P., ... \& Purani, K. (2015), "The relationship between consumer ethnocentrism, cosmopolitanism and product country image among younger generation consumers: The moderating role of country development status", International Business Review, Vol. 24 No. 3, pp. 380-393. 
Kates, S. M., and Goh, C. (2003), "Brand Morphing--Implications for Advertising Theory and Practice", Journal of Advertising, Vol. 32 No. 1, pp. 59-68.

Keillor, B. D., D'Amico, M. and Horton, V. (2001), “Global consumer tendencies”, Psychology \& Marketing, Vol. 18 No. 1, pp.1-19.

Kolbe, R. H. and Burnett, M. S. (1991), “Content-analysis research: An examination of applications with directives for improving research reliability and objectivity", Journal of consumer research, Vol. 18 No. 2, pp. 243-250.

Laroche, M., Papadopoulos, N., Heslop, L. and Bergeron, J., (2003), “Effects of subcultural differences on country and product evaluations", Journal of Consumer Behaviour: An International Research Review, Vol. 2 No. 3, pp.232-247.

Liu, S. S. and Johnson, K. F. (2005), "The Automatic Country-of-Origin Effect on Brand Judgments", Journal of Advertising, Vol. 34 No. 1, pp. 87-98.

Liu, Y., Tao, W. and Tsai, W. H. S. (2017), “Global versus local consumer culture positioning in a transitional market: Understanding the influence of consumer nationalism”, International Journal of Strategic Communication, Vol. 11 No. 4, pp. 344-360.

Lu, I. R. R., Heslop, L. A., Thomas, D. R., and Kwan, E. (2016), “An examination of the status and evolution of country image research", International Marketing Review, Vol. 33 No. 6, pp. $825-850$.

Makri, K., Papadas, K. \& Schlegelmilch, B. (2019), “Global-local consumer identities as drivers of global digital brand usage", International Marketing Review, Vol. 36 No. 5, pp. 702-725

Melnyk, V., Klein, K., \& Völckner, F. (2012), “The double-edged sword of foreign brand names for companies from emerging countries”, Journal of Marketing, Vol. 76 No. 6, pp. 21-37. 
Meyers-Levy, J., and Tybout, A. M. (1989), "Schema congruity as a basis for product evaluation", Journal of consumer research, Vol. 16 No. 1, pp. 39-54.

Michaelidou, N., and Dibb, S. (2008), “Consumer involvement: a new perspective”, The Marketing Review, Vol. 8 No.1, pp. 83-99.

Moriarty S. (2004), Visual semiotics theory, in Handbook of visual communication: Theory, methods, and media, edited by Smith, K. L., Moriarty, S., Kenney, K., and Barbatsis, G. (Eds.). Routledge.

Mueller, B. (1996), International advertising: Communicating across cultures, Wadsworth Publishing Company.

Nijssen, E. J. and Douglas, S. P. (2011), “Consumer world-mindedness and attitudes toward product positioning in advertising: An examination of global versus foreign versus local positioning”, Journal of International Marketing, Vol. 19 No. 3, pp. 113-133.

Okazaki, S. Mueller, B. and Taylor, C. R. (2010), “Global consumer culture positioning: testing perceptions of soft-sell and hard-sell advertising appeals between U.S. and Japanese consumers", Journal of International Marketing, Vol. 18 No. 2, pp. 20-34.

Onkvisit, S., and Shaw, J. J. (1999), "Standardized international advertising: some research issues and implications", Journal of Advertising Research, Vol. 39 No. 6, pp. 19-24.

Özsomer, A. (2012), “Adoption of global consumer culture: the road to global brands', in Handbook of Research on International Advertising, edited by Okazaki, S. Edward Elgar. Özsomer, A. (2019), "Some recent influences on global consumer culture: Digital networked technologies, emerging market brands and bottom of the pyramid consumers", International Marketing Review, Vol. 36 No. 4, pp. 548-552. 
Petrovici, I. (2013), "Hermeneutical aspects concerning the aesthetics of the web design", European Journal of Science and Technology, Vol. 9, No. 1, pp. 133-142.

Pharr, J. M. (2005), "Synthesizing country-of-origin research from the last decade: is the concept still salient in an era of global brands?", Journal of Marketing Theory and Practice, Vol. 1, No. 4, pp. 34-45.

Pieterse, J. N. (2004), Globalization or empire?, Routledge.

Pollay, R. W. (1983), "Measuring the cultural values manifest in advertising”, Current issues and research in advertising, Vol. 6 No. 1, pp. 71-92.

Poole, M. S., and Folger, J. P. (1981), "A method for establishing the representational validity of interaction coding systems: Do we see what they see?", Human Communication Research, Vol. 8 No. 1, pp. 26-42.

Reuters (2019), "Turkey moves to oversee all online content, raises concerns over censorship", available at: https://www.reuters.com/article/us-turkey-internet-censorship/turkey-moves-tooversee-all-online-content-raises-concerns-over-censorship-idUSKCN1UR539. (accessed $17^{\text {th }}$ March, 2020)

Rosa, F., Sillani, S. and Vasciaveo, M., (2017), “Cross-cultural consumer behavior: Use of local language for market communication-A study in region Friuli Venetia Giulia (Italy)", Journal of Food Products Marketing, Vol. 23 No 6, pp.621-648.

Zeugner-Roth, K. P., and Bartsch, F. (2019), “COO in print advertising: Developed versus developing market comparisons", Journal of Business Research, in press.

Salnikova, E., and Grunert, K. G. (2020), "The role of consumption orientation in consumer food preferences in emerging markets", Journal of Business Research, Vol. 112, No. 2020, pp. $147-159$. 
Samiee, S. (2011), "Resolving the impasse regarding research on the origins of products and brands", International Marketing Review, Vol. 28 No. 5, pp. 473-485.

Scott, L. M. (1994). "Images in advertising: The need for a theory of visual rhetoric", Journal of Consumer Research, Vol. 21 No. 2, pp. 252-273.

Sobh, R., Singh, N., Chun W., and Benmamoun, M. (2018), "Localizing to Arabic consumers: Insights from print advertising”, Journal of Marketing Communications, Vol. 24 No. 2, pp. 190-211.

Statista (2017), "Media usage in Europe - Statistics \& Facts”, available at https://www.statista.com/topics/4039/media-usage-in-europe/ (accessed 20 $0^{\text {th }}$ March, 2018)

Statistictime (2018), “statistic times”, available at; http://statisticstimes.com/index.php

Statista (2018), "Year-over-year change of advertising expenditure in selected countries from 2016 to 2018", available at: https:/www.statista.com/statistics/276805/global-advertisingmarket-forecast/ $\left(\right.$ accessed $5^{\text {th }}$ February, 2019)

Steenkamp, J. B. E. (2019), "Global versus local consumer culture: theory, measurement, and future research directions", Journal of International Marketing, Vol. 27 No. 1, pp. 1-19.

Steenkamp, J. B. E., Batra, R., and Alden, D. L. (2003), "How perceived brand globalness creates brand value", Journal of International Business Studies, Vol. 34 No. 1, pp. 53-65.

Steenkamp, J. B. E., and De Jong, M. G. (2010), “A global investigation into the constellation of consumer attitudes toward global and local products”, Journal of Marketing, Vol. 74 No. 6, pp. $18-40$.

Stemler, S. (2001), “An overview of content analysis: practical assessment, research and evaluation", available at: http://PAREonline.net/getvn.asp?v=7\&n=17 (accessed $2^{\text {nd }}$ March, 2018) 
Strizhakova, Y., Coulter, R. A., and Price, L. L. (2008), “Branded products as a passport to global citizenship: Perspectives from developed and developing countries", Journal of International Marketing, Vol. 16, No. 4, pp. 57-85.

Taylor, C. R., and Okazaki, S. (2015), "Do global brands use similar executional styles across cultures? A comparison of US and Japanese television advertising", Journal of Advertising, Vol. 44 No. 3, pp. 276-288.

Terpstra, V., and Kenneth, D. (1991), The Cultural Environment of International Business, Southwestern Publishing Company, Cincinnati.

UN (2014), “Country classification”, available at: https://www.un.org/en/development/desa/policy/wesp/wesp_current/2014wesp_country_class ification.pdf (accessed $5^{\text {th }}$ January, 2020)

Vaughn, R. (1980), "How advertising works: A planning model”, Journal of advertising research, Vol. 20 No. 5, pp. 27-33.

Verlegh, P. W., and Steenkamp, J. B. E. (1999), “A review and meta-analysis of country-oforigin research", Journal of economic psychology, Vol. 20 No. 5, pp. 521-546.

Walker, C. (1996), “Can TV save the planet?” American Demographics, Vol. 18 No. 5, pp. $42-$ 46.

Weber, R. P. (1990), Basic content analysis, Sage, CA: Beverly Hills.

Westjohn, S. A., Singh, N., and Magnusson, P. (2012), "Responsiveness to global and local consumer culture positioning: A personality and collective identity perspective", Journal of International Marketing, Vol. 20 No. 1, pp. 58-73.

Worldometer (2019), “GDP per Capita", available at: https://www.worldometers.info/gdp/gdpper-capita/. (accessed $6^{\text {th }}$ January, 2020) 
Zhou, N., and Belk, R. W. (2004), "Chinese consumer readings of global and local advertising appeals", Journal of Advertising, Vol. 33 No. 3, pp. 63-76. 